\title{
INDISCERNIBILIDADE E IDENTIDADE EM QUÍMICA: ASPECTOS FILOSÓFICOS E FORMAIS
}

\author{
JAISON SCHINAIDER \& DÉCIO KRAUSE \\ Universidade Federal de Santa Catarina (UFSC) \\ Brasil
}

jaisonsc@gmail.com

deciokrause@gmail.com

Received: 06.05.2013; Accepted: 24.09.2013

\begin{abstract}
Resumo: Neste artigo tratamos, de um ponto de vista formal e filosófico, com alguns conceitos que fazem parte da química usual. As teorias da química, e seus conceitos, normalmente são apresentadas de um ponto de vista informal (não axiomatizada), e isso pode trazer dificuldades filosóficas (embora a química propriamente - bem como também as outras disciplinas da ciência aplicada - pareçam não sofrer qualquer restrição quanto a isso). Aqui estaremos ocupados em um aspecto parti-cu-lar, que diz respeito à indiscernibilidade de alguns objetos básicos da química, tais como átomos, moléculas, bem como de seus componentes. Começamos com uma visão geral da identidade destes compostos e seus componentes a partir de uma perspectiva filosófica e, em seguida, mostramos em que sentido o conceito de identidade dos compostos químicos é problemático em relação ao conceito correspondente de identidade na lógica e matemática clássicas (que, como em geral é suposto, estão 'alicerçando' as teorias químicas). Argumentamos que, por um lado, a química parece supor que esses objetos básicos precisam ser 'idênticos' (indistinguíveis) uns aos outros (como enfatizado há muito tempo por John Dalton, como veremos.) Por outro lado, do ponto de vista formal, se a lógica subjacente à teoria atômica for a lógica clássica (que também é pano de fundo da matemática padrão), coisas idênticas devem ser a mesma coisa e logo 'colapsar' em apenas uma (e este não é o caso em química, uma vez que temos uma enorme quantidade de átomos e moléculas semelhantes, mas não apenas um). Esta aparente contradição pode ser tratada de várias perspectivas e, aqui, propomos o uso de uma teoria de conjuntos não-clássica (a saber, a teoria de quase-conjuntos) para alicerçar uma formulação axiomática de certas teoria químicas, mostrando como essa diferente base matemática pode nos levar a uma visão que está mais perto da química em si. Como esta teoria não é conhecida em geral, uma breve revisão se faz necessária. Por último, mostramos como podemos construir modelos matemáticos para átomos e moléculas utilizando esta teoria de conjuntos alternativa evitando, assim, o problema lógico acima mencionado, e discutimos um pouco da abordagem mereológica dos compostos químicos a partir dessa perspectiva quase-conjuntista.
\end{abstract}

Manuscrito - Rev. Int. Fil., Campinas, v. 37, n. 1, p. 117-164, jan.-jun. 2014. 
Palavras-Chave: indiscernibilidade, não-individualidade, quase-conjuntos, elementos químicos

Abstract: In this paper we consider some concepts that are part of standard chemistry from a formal point of view. Usually, concepts and theories of chemistry are presented in an informal way (not in an axiomatic way), and this move may present some philosophical difficulties (although chemistry itself - so as the other disciplines of applied science - does not seem to suffer with these difficulties). Here, we shall concentrate in the indiscernibility of some basic objects dealt with in chemistry, such as atoms, molecules, and their components, and we shall deal with their formal counterparts too. We begin with a general view about the identity of such elements and of their components, and then we show why the notion of identity of chemical objects is problematic with respect to the notion of identity of standard logic and mathematics (which by hypothesis underlies chemical theories). We suggest that, on the other hand, chemistry seems to suppose that some of these basic objects must be 'identical' (indistinguishable) from one another (as emphasized long time ago by John Dalton, as we shall see). On the other hand, from a formal point of view, if the underlying logic of atomic theory is classical logic (which is also the background for standard mathematics), identical things must be one and the same thing and, therefore, must collapse in just one thing. This apparent contradiction can be dealt with from different perspectives, and here we propose the use of a non-standard set theory (namely, quasi-set theory) to ground an axiomatic formulation of certain chemical theories, showing that such a move may lead us to a view closer to what says. Since this theory is not well known, a brief revision is necessary. Finally, we show how is it possible to consider mathematical models for atoms and molecules by using quasi-set theory, thus avoiding the logical problem mentioned above, and we discuss a little a mereological approach to chemical compounds by considering this quasi-set theoretical view.

Keywords: indiscernibility, non-individuals, quasi-sets, chemical elements

\section{Introdução}

Em uma série de trabalhos, temos tratado de questões acerca da individualidade (e da não-individualidade) dos objetos tratados pelas teorias quânticas (ver French e Krause (2006) para uma abordagem ampla). Neste artigo, ampliamos a discussão considerando algumas suposições admitidas pela química. Nosso principal objetivo é encontrar um modelo matemático conjuntista que sirva para descrever algumas das principais características de um composto químico como uma molécula de água, levando em conta aspectos da indiscernibilidade de seus constituintes e dela mesma. A razão por se escolher uma abordagem 
'conjuntista' tem a ver com a "capacidade redutiva" da linguagem da teoria de conjuntos, e porque ela é a mais utilizada em questões de fundamentos. ${ }^{1}$

Com efeito, um dos mais consagrados problemas da filosofia é o problema da identidade, que se apresenta à discussão filosófica de diferentes perspectivas. Por exemplo, a questão de como podemos assegurar que pessoas e demais objetos que nos cercam permanecem os mesmos, no sentido de podermos reconhecer essas entidades através do tempo, tem sido tópico de discussão desde o início da filosofia, passando pela Idade Média e chegando aos dias atuais. Esta questão (que pode ser chamada de 'identidade transtemporal'), por si só toca diversas áreas da filosofia, tais como a lógica, a filosofia da linguagem, a ontologia e a metafísica. Mas existe também, no mesmo sentido, um outro problema que concerne à noção de identidade: o problema da (in)distinguibilidade. Aqui, a questão não é "como posso reconhecer um objeto através do tempo", mas sim "como posso distinguir um objeto de outros objetos similares?", ou seja, a busca por um princípio de individualidade, que permita-nos saber porque podemos conceber um determinado objeto como sendo um determinado objeto (como o leitor irá percebendo, a discussão inicial é necessariamente algo imprecisa, mas aos poucos iremos qualificando os conceitos arrolados). Por exemplo, como posso distinguir duas canetas similares (no sentido de terem praticamente todas as suas propriedades comuns: mesmo formato, cor, marca, etc.), ou dois carros 'iguais', e assim por diante? Em uma primeira resposta, o senso-comum pode dizer que tal distinção é fácil de ser estabelecida: os objetos (similares) do mundo podem ser distinguidos entre si porque sempre apresentam uma distinção, uma marca, um arranhão, alguma coisa peculiar, ou então porque sempre podemos (pelo menos em princípio), a qualquer momento, colocar uma 'marca' em um deles de modo

\footnotetext{
${ }^{1}$ No entanto, outras possibilidades existem, como a teoria de categorias e as lógicas de ordem superior.
} 
a distinguí-lo de outros, mesmo que similares. Neste sentido, se duas canetas são muito semelhantes, eu posso 'riscar' uma caneta, ou colocar nela um rótulo, ou pintá-la de outra cor de modo que ela se torne diferente de uma outra caneta. ${ }^{2}$ Assim, os objetos do nosso contorno aparentemente sempre podem ser diferenciado porque ou há diferenças intrínsecas ou porque podemos criar 'diferenciais' para esses objetos.

Percebe-se que há, aqui, duas suposições implícitas. Primeiramente, a de que podemos (pelo menos em princípio) marcar, ou rotular um objeto de modo a diferenciá-lo de qualquer outro, por mais similares que possam ser. Este ponto é importante porque, como nos interessará abaixo, isso aparentemente não pode ser feito com átomos ou moléculas mesmo em princípio. O segundo ponto é uma posição metafísica, que a literatura filosófica atribui essencialmente a Leibniz, embora tenha raízes na antiguidade (Jammer (1966,p. 340)): não há dois objetos indiscerníveis; se são dois, necessariamente apresentam uma diferença.

Dizemos que dois objetos diferem solo numero quando, falando sem nenhum rigor, diferem somente por um ser um e o outro ser outro, contrariando o princípio metafísico leibniziano. Assumir que não há objetos que difiram solo numero é outra forma de enunciar o Princípio da Identidade dos Indiscerníveis (PII), posto explicitamente por Leibniz em várias partes de sua obra, como na "Monadologia". Segundo ele, "nunca há, na natureza, dois seres que sejam perfeitamente idênticos e nos quais não seja possível encontrar uma diferença interna, ou fundada em uma denominação intrínseca." (Leibniz $(1980, \S 9)$ ).

Podemos dizer que, de acordo com esta metafísica, os objetos que nos cercam - como pessoas, mesas e cadeiras - são indivíduos. Assim, por um indivíduo podemos informalmente entender uma entidade que

\footnotetext{
${ }^{2}$ No momento, não estamos considerando qualidades tais como 'posição espaço-temporal' porque não são intrínsicas ao objeto. Este problema, e a discussão sobre se podemos assumir um tipo de 'feixe de propriedades' que forneça identidade para o objeto, irão ser explorados (de um ponto de vista geral) na próxima seção
}

Manuscrito - Rev. Int. Fil., Campinas, v. 37, n. 1, p. 117-164, jan.-jun. 2014. 
tem as seguintes características: (i) pode ser tomada como uma unidade: é um um de algum tipo; (ii) apresenta (pelo menos em princípio) distinções relativamente a outros indivíduos, mesmo que sejam de espécie similar (isto, como visto, está implícito na hipótese do PII); (iii) um indivíduo possui identidade, no sentido de que obedece uma teoria da identidade que incorpora o PII de alguma forma (aqui, por exemplo, pode ser dito que um indivíduo respeita a teoria da identidade presente na lógica clássica, que é "leibniziana"), ${ }^{3}$ e (iv) dado um sistema formado por indivíduos, a permutação de um deles por outro, ainda que similar mas que não esteja presente no sistema, faz do sistema algo distinto do sistema original (ainda que medidas sobre este último sistema coincidam com medidas realizadas sobre o primeiro, antes da permutação). Chamaremos esta última característica de extensionalidade: indivíduos são extensionais neste sentido. ${ }^{4}$ A partir dessa definição, podemos considerar que, por exemplo, a atual rainha da Inglaterra é um indivíduo, pois pode ser considerada como uma unidade: a (única) principal pessoa da realeza britânica. Além do mais, ela apresenta distinções para com qualquer outra pessoa, por mais parecida que possa ser (há fotografias que sugerem haver pessoas muito parecidas com a rainha), de forma que podemos realmente dizer que ela tem uma identidade (nenhuma sósia tem a propriedade de ser a rainha da Inglaterra). Finalmente, se ela for substituída por outra pessoa (digamos em uma solenidade), também por mais parecida com a rainha que esta possa ser, a composição das pessoas em tal solenidade difere daquela que teria

\footnotetext{
${ }^{3} \mathrm{O}$ PII pode ser formulado em uma linguagem de segunda ordem como segue, onde $F$ é uma variável para predicados (ou propriedades) de indivíduos e $x, y$ são variáveis individuais: $\forall F(F(x) \leftrightarrow F(y)) \rightarrow x=y$. Em uma linguagem de primeira ordem, via de regra a identidade é tratada como conceito primitivo; veja-se Mendelson (1979); para detalhes, French e Krause (2006).

${ }^{4}$ Esta terminologia vem da teoria usual dos conjuntos, segundo a qual dois conjuntos são iguais se e somente se contém os mesmos elementos.
} 
todas as mesmas pessoas, mas que tivesse a rainha verdadeira em seu devido lugar. Como veremos, isso não ocorre com átomos, moléculas e com outros componentes físicos elementares.

Aliás, o problema, como veremos, está em se estabelecer em que sentido se pode dizer que átomos, moléculas ou outros objetos elementares (como elétrons, prótons, etc.) podem (se é que podem) ser ditos serem iguais ou diferentes uns dos outros. Com efeito, o fato de que tais entidades devem ser considerados como indiscerníveis é essencial em física (e química) quântica, e foi notadamente identificado por John Dalton, o pai da química moderna, quando disse (ainda em 1808 e falando em termos de "similaridade") que (Dalton (1808, p.142/3):

"[w] hether the ultimate particles of a body, such as water, are all alike, that is, of the same figure, weight, etc. is a question of some importance. From what is known, we have no reason to apprehend a diversity in these particulars: if it does exist in water, it must equally exist in the elements constituting water, namely, Hydrogen and Oxygen. Now it is scarcely possible to conceive how the aggregates of dissimilar particles should be so uniformly the same. If some of the particles of water were heavier than others, if a parcel of the liquid on any occasion were constituted principally of these heavier particles, it must be supposed to affect the specific gravity of the mass, a circumstance not known. Similar observations may be made on other substances. Therefore we may conclude that the ultimate particles of all homogeneous bodies are perfectly alike in weight, figure, etc. In other words, every particle of water is like every other particle of water, every particle of Hydrogen is like every other particle of Hydrogen, etc." 5

5 "[s]e as partículas últimas de um corpo, tal como a água, são todas similaManuscrito - Rev. Int. Fil., Campinas, v. 37, n. 1, p. 117-164, jan.-jun. 2014. 
Deste modo, apesar dos objetos dos quais fala Dalton, e que hoje podemos nos referir como "quânticos", poderem ser tomados como perfazendo certas 'unidades', pois falamos normalmente em um elétron por exemplo (hoje fazem-se experimentos de "aprisionamento" de tais entidades, mas isso não lhes confere o status de indivíduos; veja Krause (2011) e abaixo), eles não estão sujeitos ao que chamamos acima de extensionalidade. Com efeito, consoante ao pensamento de Dalton, uma das principais hipóteses da atual física quântica é o chamado Princípio de Permutabilidade, que grosso modo diz que as medidas realizadas em sistemas físicos que diferem por quanta indiscerníveis não conduzem a resultados distintos: há uma completa invariança relativamente à permutações de indiscerníveis (diferente assim do exemplo da rainha da Inglaterra antes exposto).

Somado a isso, presentemente, uma série de experimentos de precisão muito acentuada - o que faz com que seus resultados dificilmente possam ser contestados - têm corroborado algumas das previsões mais estranhas (para um ponto de vista intuitivo) da mecânica quântica, como a não-localidade e o emaranhamento (entanglement). ${ }^{6}$ Os resul-

res, isto é, da mesma forma, peso, etc. é uma questão de alguma importância. Pelo que se sabe, não há razão para considerar diversidade nesses particulares: se ela existe na água, deve igualmente existir nos elementos que constituem a água, a saber, hidrogênio e oxigênio. Agora, é difícil conceber como os agregados de partículas dissimilares poderiam ser uniformemente os mesmos. Se alguma das partículas da água fosse mais pesada do que as outras, se uma parcela do líquido em qualquer ocasião fosse constituído principalmente dessas partículas pesadas, deveria supostamente afetar a gravidade específica da massa, uma circunstância não conhecida. Observações similares podem ser feitas com outras substâncias. Portanto devemos concluir que as partículas últimas de todos os corpos homogêneos são perfeitamente similares em peso, forma, etc. Em outras palavras, qualquer partícula da água é similar a qualquer outra partícula da água, qualquer partícula de hidrogênio é similar a qualquer outra partícula de hidrogênio, etc."

${ }^{6}$ Ver, por exemplo, os resultados de Nicolas Gisin e sua equipe, da Universidade de Genebra (Branciard et. ali. (2013); Pomarico et. ali. (2011)), bem como os de Anton Zeilinger, da Universidade de Viena (Arndt, et ali. 
tados sobre não-localidade e emaranhamento apontam para uma característica dos sistemas quânticos que contesta fortemente a noção de indivíduo dada acima: no caso dos sistemas emaranhados (entangled), mesmo que saibamos que os elétrons de um átomo de Helio em seu estado fundamental têm spins opostos em uma direção escolhida, não se pode dizer (mesmo em princípio, de acordo com a teoria) qual é qual. Neste caso, insistimos, não se pode saber qual é qual de nenhum modo, na medida em que acreditemos na mecânica quântica. No entanto, no escopo da matemática usual (teoria de conjuntos e lógica clássica), duas entidades quaisquer podem sempre ser discernidos pois podemos locá-los em abertos disjuntos de alguma variedade relevante. Ou seja, no escopo "clássico", se são dois, são distintos. Como dissemos, a lógica e a matemática usuais (aquela que pode ser erigida em uma teoria padrão deconjuntos) são leibnizianas. Porém, experimentos recentes têm mostrado que os efeitos caracteristicamente quânticos como a interferência (e a não individualidade) ocorrem até mesmo com entidades que são 'grandes' para os padrões quânticos, como os fulerenos, moléculas $C_{60}$ e $C_{70}$ ou mesmo maiores (Arndt, et ali. (1999)). A questão do 'limite quântico', como se sabe, é uma das mais intrincados problemas dos estudos fundacionistas da física. No entanto, para os propósitos deste trabalho, vale notar que os experimentos atuais parecem corroborar fortemente o dito de Dalton visto acima, e isso tem consequências para os fundamentos das disciplinas envolvidas, em particular da química. Com efeito, se certas entidades, como partículas elementares, átomos e mesmo moléculas (e o que mais?) parecem contestar a noção intuitiva de indivíduo vista acima, com que tipo de entidade estamos lidando, e que matemática (e lógica) devemos considerar para captar essas nuances? Isso nos interessará mais abaixo.

Assim, vamos chamar de não-indivíduo um $x$ tal que (i) $x$ não é extensional no sentido acima. Isso significa que, dentre outras coisas, se $(1999))$.

Manuscrito - Rev. Int. Fil., Campinas, v. 37, n. 1, p. 117-164, jan.-jun. 2014. 
um sistema tem um tal $x$ como um de seus componentes (digamos, um átomo de hidrogênio em uma molécula de água, ${ }^{7}$, qualquer resultado físico (medida) não se altera se o tal átomo for (de alguma forma, mesmo que em uma suposição estritamente teórica) substituído por outro de mesma espécie. Além disso, (ii) um não-indivíduo pode ser 'isolado' de outros, o que nos confere a possibilidade de dizer que ele também pode ser visto como uma unidade, da mesma forma que os indivíduos usuais. De fato, dois elétrons separados espacialmente são discerníveis pela propriedade extrínseca de localização espaço-temporal. No entanto, isso não lhes confere a característica de indivíduo, pois qualquer permutação nos confunde e não mais podemos perceber a troca realizada, o que não é o caso com indivíduos, para os quais qualquer troca (permutação) é sensitiva (extensionalidade). Observe-se que há casos em que nem a localização espaço-temporal parece poder individualizar certos objetos quânticos, pois quando eles fazem parte de um condensado de Bose-Einstein (Ketterle (2001)), até mesmo as noções de espaço e tempo parecem não fazer sentido preciso. Com efeito, vários autores têm chamado a atenção para o fato de que as noções usuais de espaço e tempo (absolutas, relacionais ou mesmo relativistas) parecem não fazer sentido na chamada "escala de Planck", no mundo microscópico (ver Rovelli (2006)). ${ }^{8}$

\footnotetext{
${ }^{7}$ Repare que, em se chamando o tal objeto de $x$, não o estamos identificando com um indivíduo, do mesmo modo que podemos chamar de $x$ o elétron de um átomo de Hélio em seu estado fundamental que tem spin UP em uma dada direção: como estamos insistindo, tal descrição não permite que saibamos qual é o referido elétron.

${ }^{8}$ Importante mencionar que o simples isolamento (ou confinamento) de um objeto quântico, digamos, em um campo potencial, não é suficiente para conferir o status de indivíduo ao mesmo em virtude de aqui também não se obedecer ao conceito de extensionalidade visto acima, como discutido em Krause (2011).
} 


\section{A indiscernibilidade e seu problema for- mal}

Falar de objetos indiscerníveis (isto é, que partilham de todas as propriedades) é fácil de um ponto de vista intuitivo. Os dois autores deste artigo são indiscerníveis relativamente ao gosto pela filosofia e por questões de fundamentos lógicos da ciência, mas diferem por exemplo em idade e local de nascimento. Indiscernibilidade, como usualmente conceituado, refere-se então a uma ou várias 'qualidades' ou propriedades dos objetos, ainda que não saibamos muito bem do que se tratam (como se sabe, o conceito de 'propriedade' em filosofia é um tanto vago). Não obstante, o PII visto acima diz que se certas entidades possuem as mesmas propriedades, elas não são distintas, mas a mesma entidade, e tal postulado também está na base da lógica e matemática clássica, como dito antes. Mas, quais são então as propriedades que podem ser tomadas como pertencendo ao domínio do quantificador universal na formulação dada do PII em uma nota acima? Podemos assumir uma posição realista segundo a qual um objeto, mesmo um objeto quântico, possui propriedades que lhe são peculiares desde seu 'nascimento', ou devemos, como apregoa a interpretação padrão da mecânica quântica (abordagem de Copenhague), assumir que as propriedades são 'criadas' no ato de medida?' ${ }^{9}$ Isso certamente depende da interpretação assumida. Como não vamos entrar nessa discussão, usaremos o conceito de propriedade em sentido informal, como faz o físico.

Como dissemos antes, para os objetos usuais descritos pela física clássica a localização espaço-temporal é geralmente aceita como a principal característica individualizadora dos mesmos, ainda que, se aceitarmos o PII em sentido leibniziano, podemos ser impelidos a assumir que deve haver ainda alguma distinção 'interna', ou de qualidade. Levando

\footnotetext{
${ }^{9}$ Sobre isso, ver a discussão em Griffthins (2004, pp.420ss); French e Krause (2006, cap. 1).
}

Manuscrito - Rev. Int. Fil., Campinas, v. 37, n. 1, p. 117-164, jan.-jun. 2014. 
isso em conta, constata-se que historicamente há basicamente dois modos de conferirmos individualidade a um objeto; as chamadas teorias de pacotes de propriedades ('bundle theories') assumem que um indivíduo nada mais é do que a coleção de seus atributos ou propriedades. ${ }^{10}$ Aqui, a individualidade de um objeto seria dada por uma propriedade ou por uma coleção de propriedades, podendo, em alguns casos como na física clássica, ser assumida como sendo a localização espaço-temporal; os "objetos clássicos" são impenetráveis, diferindo sempre por terem trajetórias espaciais distintas. A alternativa às teorias de pacotes de propriedades é assumir uma dentre as chamadas teorias de substrato, que assumem a existência de algo a mais para além das propriedades, algo que as transcende e que não seria a elas redutível, uma forma de quid, um 'algo' que não podemos descrever por atributos pois não seria a eles redutível. Nessas teorias, seria esse "quid" que forneceria a individualidade dos objetos. Para uma discussão mais ampla, ver French e Krause (2006).

Ambas alternativas apresentam problemas. As teorias de substrato se deparam com a difícil, senão impossível, tarefa de esclarecer o que seria este 'quid'. Esta discussão não passou desapercebida ao largo da filosofia da mecânica quântica, embora seja praticamente um consenso que essa teoria, em qualquer versão, não admite substrato: nada haveria em um objeto quântico para além de suas qualidades (Redhead e Teller (1991; 1992); Teller (1995)). Eles seriam assim exatamente a soma de suas qualidades, ou características, estas prescritas pelas leis físicas que os governam (alguns os chamam por isso de de objetos 'nomológicos' (ver French e Krause (2006)). Isso nos coloca diretamente dentro das teorias de pacotes. As teorias de pacotes, por sua vez, se deparam com o problema do PII: deixando de lado a difícil questão acima mencionada acerca da natureza das propriedades, por que não

\footnotetext{
${ }^{10}$ Dentre outros, Bertrand Russell assumia esta posição (Munford (2003, cap.21).
}

Manuscrito - Rev. Int. Fil., Campinas, v. 37, n. 1, p. 117-164, jan.-jun. 2014. 
poderiam duas entidades distintas possuírem as mesmas propriedades? Ou seja, pode haver domínios onde o PII é falso? Com efeito, se os objetos quânticos e químicos, como átomos e moléculas, são indiscerníveis inclusive quanto às suas características espaço-temporais, como conciliar este fato com a lógica e matemática clássicas subjacentes, que incorporam o PII? Dito de outro modo, se aceitarmos, como parece razoável, que a noção de indiscernibilidade é essencial em física e em química, e que certas entidades parecem ser indiscerníveis em sentido forte, não podendo em determinadas circunstâncias serem discernidas de modo algum (como bosons, que podem partilhar o mesmo estado quântico), como conciliar este fato com o PII, que apregoa que nessas circunstâncias não haveria mais do que uma entidade? Vejamos rapidamente de que modo isso é incorporado no formalismo usual, o que motivará o restante de nossa discussão.

No formalismo padrão, os estados dos sistemas físicos são descritos por vetores em um adequado espaço de Hilbert. ${ }^{11}$ Por exemplo, se $H_{a}$ é um espaço de Hilbert cujos vetores $|a\rangle$ representam os estados de uma partícula $a$ e $H_{b}$ é um espaço de Hilbert cujos vetores $|b\rangle$ representam os estados de uma partícula $b$, os estados do sistema conjunto (isso pode ser estendido para um número maior de partículas), é descrito por vetores $|a\rangle \otimes|b\rangle$ do produto tensorial $H=H_{a} \otimes H_{b}$. Mas o produto tensorial não é comutativo. Isso significa que $|a\rangle \otimes|b\rangle$ é em geral diferente do sistema permutado $|b\rangle \otimes|a\rangle$. O que se usa para descrever o sistema conjunto não são esses vetores, mas vetores simétricos (no caso de bosons) e anti-simétricos (no caso de fermions): $\frac{1}{\sqrt{2}}(|a\rangle \otimes|b\rangle \pm|b\rangle \otimes|a\rangle$ ), o sinal "+" para bosons e o sinal " -"para fermions. Os vetores anteriormente citados não representam estado físico algum, o que significa que o formalismo é 'mais abundante' do que as situações físicas relevantes. ${ }^{12}$

\footnotetext{
${ }^{11} \mathrm{~A}$ abordagem via espaços de Hilbert não é a única possível, mas tem sido apresentada como a preferida tanto por físicos como (principalmente) por filósofos.

${ }^{12}$ Isso levou Redhead e Teller a falarem em 'surplus structures', que se-
} 
Os vetores simétricos são totalmente invariantes perante a permutação (dos rótulos) das partículas, enquanto que os anti-simétricos mudam de sinal. Porém, essa troca de sinais não importa, pois as propriedades relevantes são tomadas a partir dos quadrados de tais vetores, o que independe do seu sinal. Ora, isso obviamente é um truque: estamos utilizando uma matemática na qual não se pode ter objetos indistinguíveis sem serem o mesmo objeto (pelo Princípio de Leibniz) para tratar de coisas que não apresentam qualquer diferença em princípio. Ao nomearmos as partículas, os vetores $|a\rangle$ e $|b\rangle$ já as diferenciam pelos rótulos, e a escolha dos vetores simétricos e anti-simétricos somente esconde essa distinção metafísica.

Usando este artifício de selecionar vetores simétricos e anti-simétricos, contorna-se formalmente o problema da matemática (e da lógica) subjacente incorporar o PII como um de seus teoremas. Assim, para todos os efeitos práticos, é como se tratássemos de partículas indiscerníveis o tempo todo. Todavia, o que está na verdade acontecendo é que estamos primeiramente rotulando os vetores (e assim promovendo uma diferenciação, já que na matemática clássica não temos como agir diferentemente), e depois disso argumentamos que os rótulos não importam e que podem ser trocados entre si sem problemas. ${ }^{13}$. Ora, do ponto de vista dos fundamentos, se os objetos em questão são indiscerníveis, isso

riam estruturas excedentes no formalismo que não têm correspondente físico (Redhead e Teller $(1991 ; 1992)$ ).

${ }^{13}$ Ver Ball (2003, p.378ss); Kuhn et. ali. (2009, p. 103ss); Turrell (2002, p.262ss); Mcquarrie e Simon (1997, p.286ss). Em geral, o químico não toca nesse assunto, tomando a indistinguibilidade como algo não problemático (é o caso em Cox (2004), e em Murphy et. ali. (2008)), ou então fala sobre a 'construção' dos elementos somente de um ponto de vista histórico (caso de Klein e Lefévre (2007)). Muitas vezes, parece que o químico parece não ter consciẽncia do problema da indistinguibilidade dos elementos microscópicos frente à matemática clássica que utiliza, tomando — quando é forçado a pensar no assunto - conjuntos (e conceitos relacionados) para fundamentar suas teorias em um 'modo natural': é o caso em Restrepo et. ali., (2006), por exemplo. 
deveria ser considerado $a b$ initio e não com assunções $a d$ hoc posteriores que somente mascaram o problema. Ao menos filosoficamente, a questão deveria ser considerada por este lado. Desta forma, pode-se dizer que, na questão fundacionista, dever-se-ia ter uma teoria matem'atica que nos permitisse tratar de objetos indistinguíveis desde o princípio, em conformidade com as nossas melhores teorias. Fugir desta problemática, e assumir assim objetos indistinguíveis que mesmo partilhando de todas as propriedades não se 'tornam apenas um', é é uma das finalidades da teoria de quase-conjuntos que descrevemos brevemente a seguir.

\section{Conjuntos e a estrutura dos componen- tes químicos}

Como dissemos, no caso particular acima, em que estamos falando de lógica, a validade do PII na lógica subjacente ao formalismo da mecânica quântica faz com que objetos indiscerníveis, sendo mais de um, necessariamente sejam distintos. ${ }^{14}$ Em se tratando de um número finito de tais entidades, a situação se complica ainda mais pois podemos nomeá-los, digamos $a_{1}, \ldots, a_{n}(n \geq 2)$, e então como enfatizado já estaríamos fazendo uma distinção em sentido forte que parece contrariar a ideia da indiscernibilidade. ${ }^{15}$ Enfatizemos que isso se deve à lógica (matemática incluída) subajacente: não há escape. Em tal contexto, não podemos falar de entidades que não apresentem diferenças exceto

\footnotetext{
${ }^{14}$ Há na literatura discussões sobre formas distintas do PII e de sua validade na física quântica, obtidas modificando-se o domínio do quantificador em $\forall F$. Mas isso é problemático, pois a restrição a algumas propriedades altera o princípio, que já não mais fala de todas as propriedades, mas de algumas.

${ }^{15}$ No entanto, a possibilidade de 'nomear' os objetos quânticos é por si só problemática e tem sido questionada há muito tempo. Sobre isso, ver French e Krause (2006, cap. 6).
} 
se utilizarmos algum truque matemático que esconda o fato de que, na matemática padrão, todo objeto é um indivíduo.

Não obstante, esta questão da possibilidade de representarmos de um modo conjuntista objetos indiscerníveis, entres os quais aqueles que importam à química merece consideração.

\subsection{Sobre a elaboração de teorias}

Falando por alto, podemos sustentar que o cientista elabora suas teorias, em especial as da física, usando alguma matemática. Tal matemática pode ser em geral obtida na teoria ZFC (Zermelo-Fraenkel com o axioma da escolha, que aqui é tomada porque tem sido a mais considerada nessas discussões), que serve para alicerçar os conceitos necessitados pelo cientista (como por exemplo funções, derivadas, equações diferenciais, medidas, etc., tudo isso pode ser obtido em ZFC). essas teorias permitem ao cientista considerar — ou 'modelar' — dentro desse construto conjuntista, os objetos físicos com os quais trabalha. Assim, do ponto de vista dos fundamentos, uma molécula de água passa a ser representada por um objeto de ZFC, um conjunto (abaixo, veremos uma das possibilidades). O cientista associa diretamente as entidades matemáticas àquelas com as quais lida em laboratório, raciocinando como se de fato os vetores, por exemplo, descrevessem situações físicas "concretas". É claro que o modo como se dá tal ligação é matéria de dabate na filosofia: os antigos positivistas lógicos, por exemplo, falavam em relações coordenadoras para atribuir um certo conteúdo empírico a pelo menos alguns termos teóricos (Suppe (1977)), mas a questão é delicada e não há pleno consenso sobre como vincular as nossas teorias com 'realidade'. Isso no entanto não impede a prática científica. No que nos concerne, desejamos investigar de um modo preliminar (na verdade, ao menos levantar o problema) de que modo certos objetos considerados pela química podem ser assim modelados, se é que podem.

Vejamos um caso específico, o de uma molécula de água. Sabemos Manuscrito - Rev. Int. Fil., Campinas, v. 37, n. 1, p. 117-164, jan.-jun. 2014. 
da química usual que uma de tais moléculas é formada por dois átomos de hidrogênio e um de oxigênio, conforme o esquema bastante tosco da Figura 1.

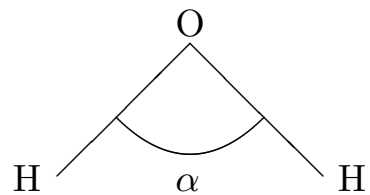

Figura 1: Representação esquemática da estrutura de uma molécula de água, indicando-se os elementos que a compõem. O ângulo entre os átomos de hidrogênio é de $\alpha=104,95^{\circ}$, e a distância entre o átomo de oxigênio e cada um dos átomos de hidrogênio é de 0,9504 Å. Não há diferenças intrínsecas entre duas moléculas de água: elas são indiscerníveis, e o mesmo se dá com seus elementos constituintes de mesma espécie.

O que temos na figura é um esquema da fórmula estrutural da molécula, envolvendo ângulos e distâncias. Importante salientar que, como dissemos, não importa a identificação "particular" do átomo de oxigênio ou dos átomos de hidrogênio. A única coisa que vem ao caso é que sejam átomos desses dois tipos. Sua individualidade (por exemplo, levar em conta "aquele" particular átomo de hidrogênio) não entra na representação da molécula, ou seja, para todos os efeitos de medida, em uma reação química por exemplo, é indiferente se na composição da molécula entra um particular átomo de oxigênio ou outro; o mesmo se dando com respeito aos átomos de hidrogênio. Duas moléculas de água, dois átomos de uma mesma substância, assim como dois elétrons, dois prótons, etc. são indiscerníveis ${ }^{16}$. O que parece relevante nessas questões são apenas o tipo dos objetos considerados (hidrogênio, oxi-

\footnotetext{
${ }^{16}$ Com efeito, exemplifiquemos esse ponto com uma reação química como a seguinte:

$$
\mathrm{NO}+\mathrm{O}_{3} \rightarrow \mathrm{NO}_{2}+\mathrm{O}_{2}
$$
}


gênio, elétron, próton, ...) e a quantidade deles, e eles não importam como indivíduos.

Voltando ao tema anterior, perguntamos: podemos representar tudo isso em uma linguagem adequada baseada na teoria de conjuntos? Isso faz sentido se considerarmos que se estamos pensando nos fundamentos da química, e se aceitamos, como parece bastante evidente, que seus conceitos matemáticos se reduzem a conceitos conjuntistas, pode-se esperar (malgrada a dificuldade) que haja sim alguma forma de redução conjuntista das entidades mais básicas com as quais estejamos tratando.

Sendo assim, se aceitarmos que este reducionismo é possível, e que podemos formalizar uma área de conhecimento (como a química) fundamentando-a na matemática padrão, uma forma de se fazer isso é acrescentar (além dos axiomas matemáticos já envolvidos) axiomas específicos que capturam os princípios básicos desta área. A matemática, como dito, pode por sua vez (em certo sentido) ser formalizada utilizando uma teoria de conjuntos como ZFC. Desta forma, se formalizarmos uma área da ciência usando a matemática, nós já nos comprometemos de início com os princípios básicos da teoria de conjuntos que estamos usando. O problema (como dissemos acima) é que os axiomas dessas usuais teorias de conjuntos também são inadequados para representar coleções de objetos indistinguíveis porque, nessas teorias, os elementos de um conjunto são tomados como sendo indivíduos (como disse Georg Cantor, são objetos "distintos de nossa intuição e pensa-

onde uma molécula de óxido nítrico (NO) reage com uma molécula de ozônio $\left(\mathrm{O}_{3}\right)$ para produzir uma molécula de dióxido de nitrogênio $\left(\mathrm{NO}_{2}\right)$ e uma molécula de oxigênio $\left(\mathrm{O}_{2}\right)$. Obviamente, não importa qual particular átomo de oxigênio (e há três deles) é capturado pela molécula de óxido nítrico para formar o dióxido de nitrogênio; a única coisa que importa é que o que é capturado seja uma molécula de oxigênio, e não uma em particular, pois elas são indiscerníveis e não apresentam distinções (isso pode parecer óbvio, mas não é, como vimos evidenciando). 
mento"17), e também incorporam o PII de alguma forma. Com isso, novamente acabamos por ficar comprometidos com uma teoria da identidade e da individualidade (e assim com toda a problemática atrelada a tais conceitos) quando usamos as teorias de conjuntos clássicas (que enfatize-se, estão sustentanto a matemática padrão) para tratar questões de fundamento como as que estamos aqui explorando. Como na formalização de uma ciência as teorias desta ciência se tornam dependentes da matemática que usamos, as teorias químicas - que são nosso caso - também não podem apenas 'recusar' os teoremas de tais bases lógicas e matemáticas.

Como dissemos acima, podemos lançar mão de artifícios ad hoc para tratar desse problema ou podemos, de um modo que nos parece mais natural, mudar o alicerçe matemático em que tais teorias estão fundamentadas. Assim, uma das soluções possíves (e a que será aventada aqui) é mudar a teoria de conjuntos que subjaz nossa matemática e nossas teorias químicas. O que necessitamos, é uma teoria de conjuntos em que se possar falar sobre (e manipular) o número de partículas indistinguíveis nos átomos sem cairmos nos problemas clássicos citados. Além disso, precisamos conseguir saber quantas partículas indistinguíveis existem em um certo átomo mesmo sem poder distinguí-las. Com efeito, consideremos os seis elétrons do nível $2 \mathrm{p}$ de um átomo de sódio: $1 \mathrm{~s}^{2} 2 \mathrm{~s}^{1} 3 \mathrm{~s}^{2} 2 \mathrm{p}^{6} 4 \mathrm{~s}^{1}$. Sabemos que são seis elétrons, mas também não podemos contê-los pelos padrões conjuntistas clássicos. Para tanto, teríamos que representá-los (modelá-los) como constituindo um conjunto, e teríamos que definir uma função bijetora entre este conjunto e o ordinal $6=\{0, \ldots, 1\}$. Mas se não podemos diferenciar os elétrons um do outro, como dito, como dizer que eles formam um 'conjunto' na acepção cantoriana, e como definir tal função sem poder discernir um elétron do outro? Desta forma, necessitamos também de um modo de saber quantos são que não seja via métodos ordinários que pressupõem uma

\footnotetext{
${ }^{17}$ Para detalhes, ver French e Krause (2006, cap. 6).
} 
contagem, o que requer de antemão a distinção entre os objetos. Nossa teoria de conjuntos alternativa deverá também refletir tal fato: deveremos ter assim um cardinal mas não um ordinal: devemos poder "saber quantos' sem necessidade de diferenciação (mesmo em princípio), ou seja, sem ordinalidade.

\section{A teoria de quase-conjuntos}

Para dar conta de todos esses 'conflitos' de identidade frente à questão formal, pensamos que podemos então adotar uma teoria de conjuntos não-clássica chamada de teoria dos quase-conjuntos $\mathfrak{Q}$. Esta é construída do seguinte modo ${ }^{18}$. Intuitivamente falando, um quase conjunto (qset) é uma coleção de objetos que podem ser indistinguíveis sem que isso acarrete que sejam idênticos. Na teoria $\mathfrak{Q}$, expressões como $x=y$ (bem como sua negação $x \neq y$ ), não são bem formadas quando as entidades denotadas por $x$ e por $y$ são o que é chamado na teoria de $m$-átomos ou q-objetos, que intuitivamente falando representam os objetos quânticos. No entanto, uma parte da teoria funciona exatamente como a teoria "clássica" ZFC, de modo que em $\mathfrak{Q}$ podemos reconstruir toda a matemática tradicional. Quase-conjuntos (qsets) podem portanto ser de uma dos seguintes tipos: (a) qsets que são "conjuntos", cópias exatas dos conjuntos de ZFC; (b) qsets "puros", cujos elementos são m-átomos. Neste caso, esses m-átomos podem ou não serem todos indiscerníveis uns dos outros (sem que isso implique que sejam "o mesmo" objeto - logo, PII não vale para m-átomos, e (c) qsets mistos, que podem ter m-átomos e outros objetos "clássicos" como elementos. $\mathrm{Na}$ "parte clássica" da teoria, há ainda os M-átomos, que funcionam em $\mathfrak{Q}$ como os Urelemente das teorias de conjuntos com átomos (ZFU, a teoria de Zermelo-Fraenkel com Urelemente - ver Suppes (1972)).

\footnotetext{
${ }^{18}$ Usaremos aqui apenas um fragmento da teoria $\mathfrak{Q}$ que é importante para nosso trabalho. Para mais detalhes, ver French e Krause (2006, cap. 7).
}

Manuscrito - Rev. Int. Fil., Campinas, v. 37, n. 1, p. 117-164, jan.-jun. 2014. 
Assim, $\mathfrak{Q}$ é uma teoria com dois tipos de átomos, e para os m-átomos, a noção de identidade (dada pelo predicado binário "=") não se aplica, mas há uma relação binária de indiscernibilidade, representada pelo predicado binário "三", conforme abaixo. Consequentemente, a lei reflexiva da identidade $\forall x(x=x)$ não vale irrestritamente, de modo que este sistema tem por base uma lógica não-reflexiva.

A relação primitiva $\equiv$ tem as propriedades de uma relação de equivalência. Além do mais, como veremos abaixo, podemos definir um conceito de identidade extensional que poderá ser aplicado para todos os objetos exceto para os m-átomos, e esta relação tem as mesmas propriedades da identidade clássica das teorias de conjunto padrão para os objetos aos quais se aplica. Com isto, os elementos de um qset puro (que contêm somente m-átomos como elementos) podem ser indistinguíveis sem que sejam idênticos. Em outras palavras, $x \equiv y$ não implica $x=y$.

Exibiremos agora algumas noções gerais da teoria $\mathfrak{Q}$. A linguagem de $\mathfrak{Q}$ encerra os seguintes símbolos primitivos específicos: três predicados unários $m, M$ e $Z$, dois predicados binários $\equiv$ e $\in$ e um símbolo funcional unário $q c$. Os termos desta linguagem são as variáveis individuais, que simbolizaremos por $x, y$, etc., e as expressões da forma $q c(x)$. O termo $q c(x)$ indica o quase-cardinal de $x$, e será comentado abaixo. As fórmulas atômicas são as expressões da forma $m(x), M(x)$, $Z(x), x \in y$ e $x \equiv y$. Intuitivamente, $m(x)$ diz que $x$ é um m-átomo; $M(x)$ diz que $x$ é um M-átomo, $Z(x)$ diz que $x$ é um "conjunto", $x \in y$ diz que $x$ é elemento de $y$ e $x \equiv y$ diz que $x$ é indiscernível de $y$.

DEFINIÇÃO 4.1 .

1. [qset] $Q(x):=\neg(m(x) \vee M(x))$ (em palavras, um qset é aquilo que não é um átomo).

2. [qset puro de objetos indiscerníveis] $P(X):=Q(x) \wedge \forall y(y \in x \rightarrow$ $m(y)) \wedge \forall y \forall z(y \in x \wedge z \in x \rightarrow y \equiv z)$. 
3. [Dinge] $D(x):=M(x) \vee Z(x)$ (em seu trabalho original de 1908 (Zermelo (1967)), Zermelo admitiu a existência de um domínio (Beireich) cujos objetos (em alemão, Dinge) seriam os conjuntos e os Urelemente, —aqui representados pelos M-átomos-, entidades que não são conjuntos mas que podem ser elementos de conjuntos).

4. [qset cujos elementos são também qsets] $E(x):=Q(x) \wedge \forall y(y \in$ $x \rightarrow Q(y))$.

5. [Identidade extensional] $\left(x={ }_{E} y\right):=(Q(x) \wedge Q(y) \wedge \forall z(z \in$ $x \leftrightarrow z \in y)) \vee\left(M(x) \wedge M(y) \wedge \forall_{Q} z(x \in z \leftrightarrow y \in z)\right.$ ), (onde $\forall_{Q}$ é o quantificador universal relativizado a qsets. Logo, a identidade extensional não se aplica a m-átomos).

6. [subqset] $x \subseteq y:=\forall z(z \in x \rightarrow z \in y)$

7. [subqset próprio] $x \subset y:=x \subseteq y \wedge x \neq_{E} y$

Os primeiros axiomas específicos de $\mathfrak{Q}$ são os seguintes: ${ }^{19}$

(Q1) $\forall x(x \equiv x)$ [三é reflexiva];

(Q2) $\forall x \forall y(x \equiv y \rightarrow y \equiv x)$ [三 é simétrica];

(Q3) $\forall x \forall y \forall z(x \equiv y \wedge y \equiv z \rightarrow x \equiv z)$ [三 é transitiva].

(Q4) $\forall x \forall y\left(x={ }_{E} y \rightarrow(A(x) \rightarrow A(y))\right)$, com as restrições sintáticas usuais, isto é, $A(x)$ é uma fórmula qualquer e $A(y)$ advém de $A(x)$ pela substituição de algumas ocorrências livres de $x$ por $y$, dado que $y$ é livre para $x$ em $A(x)$.

Como a relação $\equiv$ tem as propriedades de uma relação de equivalência, dado um qset $x$, podemos considerar o qset quociente $x / \equiv$ das classes de equivalência de elementos indiscerníveis de $x$. Resulta da axiomática que se $x$ for um conjunto, essas classes serão unitárias, ou seja,

\footnotetext{
${ }^{19}$ Não listaremos todos os postulados de $\mathfrak{Q}$ aqui, mas somente os que forem necessários. Para uma visão geral, ver os trabalhos mencionados nas nossas referências.
} 
para os objetos "clássicos", a indiscernibilidade e da identidade coincidem, o que reflete o caráter leibinziano da teoria em sua contraparte "clássica".

Em $\mathfrak{Q}$, postula-se que a indistinguibilidade (indiscernibilidade) implica igualdade extensional (a conversa segue-se como teorema) para os objetos clássicos ( $M$-átomos e conjuntos). Sendo assim, para quaisquer dois objetos clássicos da teoria $\mathfrak{Q}$, se eles forem indistinguíveis serão extensionalmente iguais, e todas as outras propriedades lógicas da igualdade clássica são provadas de modo usual para estes objetos. Por fim, ressaltamos a distinção entre identidade extensional e indistinguibilidade primitiva. Pelos axiomas e teoremas acima, a relação de indistinguibilidade $\equiv$ permite a substitutividade de todos os símbolos não-lógicos primitivos, exceto o de pertinência. Isto é, se $B$ é um predicado dentre $m, M, Z$, então $B(x) \wedge x \equiv y \rightarrow B(y)$ é um teorema. Se isto fosse possível também para $\in$ (pertinência), então dado que $\equiv$ é reflexiva (axioma (Q1)), deveríamos ter substitutividade para $\equiv$ e esta não se tornaria diferente da forma usual da identidade (dito de outra forma, $\equiv$ colapsaria na identidade usual). Mas com relação à pertinência este não é o caso, já que de $x \in w \wedge y \equiv x$ não implica $y \in w$ pois a teoria $\mathfrak{Q}$ não tem axiomas que permitam derivar este fato. Desta forma, e isso é importante, indistinguibilidade dos $m$-átomos não se torna a identidade 'padrão' e, quando precisarmos falar que temos por exemplo "dois" objetos, poderemos fazer isso selecionando adequados qsets de m-átomos com quase-cardinal 2, e isso nos conduzirá somente à sua discernibilidade, e não à sua diferença (aqui na acepção antônima de igualdade) ( $c f$. Arenhart e Krause (2007).)

O conceito primitivo de quase-cardinal intuitivamente representa a quantidade de objetos em um qset. Um quase-cardinal é um cardinal, mas nem todos os qsets têm um quase-cardinal. ${ }^{20} \mathrm{O}$ conceito de car-

\footnotetext{
${ }^{20} \mathrm{Na}$ formulação original da teoria, todo qset possuía um quase-cardinal, mas relaxamos esta exigência de forma a que a teoria possa ser aplicada
} 
dinal é definido como de hábito na parte clássica da teoria. Com isto, certos qsets (aqueles nos quais os elementos são q-objetos) podem ser ter um quase-cardinal, mas seus elementos não podem ser ordenados (não têm um ordinal associado, como se demonstra) ou identificados por nomes. A partir de tal conceito, podemos falar sobre os vinte prótons do núcleo de um átomo de cálcio $\left({ }_{20} \mathrm{Ca}\right)$ sem que seja possével identificar os prótons individuais, o que na matemática usual só pode ser alcançado "esquecendo-se"que eles teriam idenidade. Assim, com os axiomas da teoria de quase-conjuntos $\mathfrak{Q}$, podemos consistentemente conceber um qset de elementos ( $m$-átomos) indistinguíveis com um quase-cardinal igual a 20, e para os quais não podemos atribuir individualidade.

$\mathrm{Na}$ interpretação pretendida, os m-átomos representam os objetos quânticos mais básicos, como elétrons e protons dentre outros. Certamente devemos poder considerar, por exemplo que elétrons se distinguem de protons, e mesmo que elétrons possam ser discernidos entre si em certas situações. Isso tudo pode ser compatibilizado em $\mathfrak{Q}$. Agora suponha (ainda falando informalmente) que tenhamos duas coleções contendo como elementos dois prótons, três elétrons e dois neutrons (isso poderia ser, grosso modo, um átomo de lítio). Certamente uma tal coleção deveria ser indiscernível de qualquer "outra" contendo a mesma quantidade de elementos do mesmo tipo (qualquer "outro" átomo de lítio). Isso é capturado na teoria $\mathfrak{Q}$ por meio de um axioma, chamado de Axioma da Extensionalidade Fraca (uma forma mais fraca do Axioma da Extensinalidade da teoria de conjuntos usual), que é enunciado como abaixo, para o qual necessitamos da seguinte definiçãoo:

[Axioma da Extensionalidade Fraca]

DEFINIÇÃo 4.2. Para qsets $x$ e $y$ não vazios:

também às teorias quânticas de campos, nas quais há criação e aniquilamento de partículas.

Manuscrito - Rev. Int. Fil., Campinas, v. 37, n. 1, p. 117-164, jan.-jun. 2014. 
1. $\operatorname{Sim}(x, y):=\forall z \forall t(z \in x \wedge t \in y \rightarrow z \equiv t)$. Neste caso dizemos que $x$ e $y$ são q-similares.

2. $\mathrm{Q} \operatorname{Sim}(x, y):=\operatorname{Sim}(x, y) \wedge q c(x)={ }_{E} q c(y)$. Isto é, $x$ e $y$ são são q-similares e tem a mesma quase-cardinalidade.

Temos então o axioma seguinte"

[Axioma da Extensionalidade Fraca] qsets que têm a mesma quantidade de elementos "do mesmo tipo"são indistinguíveis. Em símbolos:

$$
\begin{aligned}
\forall_{Q} x \forall_{Q} y\left(\left(\forall_{z}(z \in x / \equiv \rightarrow \exists t(t \in y / \equiv \wedge Q \operatorname{Sim}(z, t)))\right)\right. \\
\wedge \forall t(t \in y / \equiv \rightarrow \exists z(z \in x / \equiv \wedge \mathrm{QSim}(t, z))) \rightarrow x \equiv y),
\end{aligned}
$$

onde, recordemos, $x / \equiv$ significa o qset quociente de algum qset $x$ pela relação de equivalêcia $\equiv$. Desta forma, este axioma permite manipularmos formalmente outra faceta da teoria quântica, exatamente aquela de que se trocarmos um próton de cálcio de um átomo, por um outro próton de cálcio da minha mesa, por exemplo, o 'cálcio final' resultante permanece com exatamente as mesmas propriedades. Com efeito, nas palavras de Penrose (1989, p. 32):

"[a]ccording to quantum mechanics, any two electrons must necessarily be completely identical [in the physicist's jargon: indistinguishable], and the same holds for any two protons and for any two particles whatever, of any particular kind. His is not merely to say that there is no way of telling the particles apart; the statement is considerably stronger that that. If an electron in a person's brain were to be exchanged with as electron in a brick, then the state of the system would be exactly the same state as it was before, not merely indistinguishable from it! The same holds for protons and for any other kind of 
particle, and for the whole atoms, molecules etc. If the entire material content of a person were to be exchanged with the corresponding particles in the bricks of his house then, in a strong sense, nothing would be happened whatsoever. What distinguishes the person from his house is the pattern of how his constituents are arranged, not the individuality of the constituents themselves" 21

Nas teorias de conjunto padrão, podemos expressar essa 'troca' dizendo que se $w \in x$, então $(x-\{w\}) \cup\{z\}=x$, mas isso corre se e somente se $z=w$ por força do Axioma da Extensionalidade. Mas, na teoria de quase-conjuntos, pode-se provar o seguinte teorema (aqui só enunciado), $\operatorname{com} z^{\prime}$ e $w^{\prime}$ denotando quase-conjuntos com quase-cardinal 1 cujos elementos são indiscerníveis de $z$ e $w$ repectivamente:

Inobservabilidade de Permutações: Seja $x$ um quase-conjunto finito tal que $x$ não contém todos os elementos indistinguíveis de $z$, onde $z$ é um m-átomo tal que $z \in x$. Se $w \equiv z$ e $w \notin x$, então existe $w^{\prime}$ tal que se

$$
\left(x-z^{\prime}\right) \cup w^{\prime} \equiv x .
$$

Assim, supondo que $x$ tem $n$ elementos, se 'trocarmos' seus ele-

${ }^{21}$ [d]e acordo com a mecânica quântica, quaisquer dois elétrons devem necessariamente ser completamente idênticos [no jargão físico: indistinguíveis], e o mesmo vale para quaisquer dois protons e para quaisquer duas partículas, de qualquer tipo. Isso não é meramente um modo de falar de duas partículas separadas; a afirmativa é consideravelmente mais forte do que isso. Se um elétron do cérebro de uma pessoa fosse trocado por um elétron de uma parede, então o estado do sistema seria exatamente o mesmo que ele era antes, e não meramente indiscernível dele! O mesmo vale para prótons e para qualquer outro tipo de partícula, e mesmo para átomos, moléculas, etc. Se o conteúdo material todo de uma pessoa fosse trocado pelas correspondentes partículas das paredes de sua casa, em um sentido forte, nada teria acontecido. O que distingue a pessoa de sua casa é a forma pela qual seus constituintes estão arranjados, e não a individualidade dos constituintes." 
mentos $z$ por correspondentes elementos indistinguíveis $w$ (do ponto de vista conjuntista isso significa efetuar a operação $\left.\left(x-z^{\prime}\right) \cup w^{\prime}\right)$, então o quase-conjunto restultante permance indistinguível do original. Isto prova que com a teoria de quase-conjuntos $\mathfrak{Q}$, podemos expressar formalmente que 'permutações não são observáveis'.

Desta forma, tendo quase-conjuntos, podemos considerar coleções de elementos indicerníveis sem que resultem ser o mesmo elemento. Com isso, podemos formar qsets que representem elétrons, nêutrons e prótons e, em sequência, com isso 'formar' (pelo menos do ponto de vista conjuntista) uniões de tais elementos, desta forma "modelando" átomos e moléculas de todas as variedades. Mas temos agora um importante ponto a enfatizar: um átomo não é somente um agregado ou um somatório de partículas atômicas elementares, de modo que a simples união de subpartículas, feita formalmente de modo aleatório, por si só não constitui um modelo adequado de um átomo real. Se quisermos 'construir' um átomo de hidrogênio, por exemplo, necessitamos que um próton e um nêutron estejam no núcleo deste átomo, e um elétron esteja orbitando ao redor deste núcleo (ou seja, na chamada 'nuvem eletrônica'). Da mesma forma, uma molécula de água não é somente a coleção de dois átomos de hidrogênio e mais um de oxigênio. Em todos esses casos, necessitamos de algo mais: a estrutura, a forma, o 'formato' do átomo ou da molécula que é, como se sabe, dependente dos átomos que compõe cada molécula particular, ou das partículas que compõe cada átomo particular. Assim, no caso da água por exemplo, necessitamos que os dois átomos de hidrogênio façam, um em relação ao outro, um ângulo de $104,45^{\circ}$ frente ao centro do átomo de oxigênio. Para se ter uma molécula de água, necessitamos que esta característica (entre outras) seja preservada. Outros tipos de moléculas, irão necessitar de outras configurações particulares. Somente na geometria molecular temos várias classificações de 'formato geométrico' para a molécula (somente para citar algumas: linear, angular, triagonal 
plana, tetraédrica e piramidal) dependentes dos 'tipos' e do número de átomos envolvidos. Com isto, a teoria da repulsão eletrônica dos pares e a teoria das ligações químicas (entre outras coisas, como dito) podemos 'construir' uma miríade de formas geométricas de moléculas e compostos químicos.

Na próxima seção, iremos então mostrar como podemos manipular, em uma estrutura matemática quase-conjuntista, estas partículas elementares para construir de uma forma bastante esquemática átomos e moléculas usando a teoria $\mathfrak{Q}$, e desta forma evitar os problemas lógicos aqui enfatizados que advêm da indistinguibilidade desses objetos.

\section{Uma abordagem formal para os compos- tos químicos indistinguíveis}

Em questões de fundamentos, tem sido comum o emprego de estruturas matemáticas para de obtermos o 'esqueleto formal' de certas áreas do conhecimento. Com efeito, o emprego das estruturas matemáticas se tornou hoje em dia uma formulações mais em voga para se entender o que são as teorias científicas, a ponto de alguns filósofos defenderem que boa parte da ciência aplicada poderia ser reduzida ao conceito matemático de estrutura. ${ }^{22}$ Claro que uma questão que se põe é exatamente como 'ligar' os objetos de tal estrutura com a realidade empírica. Trata-se de uma questão de difícil resposta, para a qual não há consenso. Nossa abordagem será, portanto, esquemática.

Nesta seção, nos interessa mostrar como podemos 'construir' (pelo menos do ponto de vista conjuntista) átomos e moléculas indicerníveis usando estes conceitos e, para tanto, teremos que primeiramente estabelecer algumas definições e ampliar a teoria $\mathfrak{Q}$ de modo a incluir alguns predicados adicionais para o nosso estudo de caso. Desta forma,

${ }^{22}$ Sobre esse ponto, veja por exemplo, da Costa e French (2003).

Manuscrito - Rev. Int. Fil., Campinas, v. 37, n. 1, p. 117-164, jan.-jun. 2014. 
seja $\epsilon, \pi$ e $\eta$ três predicados unários. Intuitivamente falando, para cada $m$-átomo $x$ da nossa teoria $\mathfrak{Q}, \epsilon(x), \pi(x) \eta(x)$ irá significar que " $x$ é um életron", " $x$ é um próton" ou que " $x$ é um nêutron", respectivamente. A partir disso, postulamos o que segue para reger o comportamento de tais predicados:

1. $\forall x(\epsilon(x) \vee \pi(x) \vee \eta(x)) \rightarrow m(x)$

2. $\forall x \epsilon(x) \rightarrow \neg \pi(x) \wedge \neg \eta(x)$

3. $\forall x \pi(x) \rightarrow \neg \epsilon(x) \wedge \neg \eta(x)$

4. $\forall x \eta(x) \rightarrow \neg \epsilon(x) \wedge \neg \pi(x)$

5. $\forall x \forall y(\epsilon(x) \wedge \epsilon(y) \rightarrow x \equiv y)$

6. $\forall x \forall y(\pi(x) \wedge \pi(y) \rightarrow x \equiv y)$

7. $\forall x \forall y(\eta(x) \wedge \eta(y) \rightarrow x \equiv y)$

Ressalta-se acima o uso do símbolo de $\equiv$ (indistinguibilidade), em detrimento ao de igualdade, devido aos motivos já expostos ${ }^{23}$

DefiniçÃo 5.1. Seja $D$ um qset tal que $q c(D)={ }_{E} n$, com $n \in \omega$ (sendo $\omega$ o conjunto dos números naturais). Todos os elementos de $D$ satisfazem um dos predicados acima, ou seja, $D$ é um qset de $m$ átomos de três tipos, os quais chamaremos por abreviação de $e^{-}, p$ e $n$, respectivamente.

Consideremos agora uma coleção $\mathfrak{C}$ de subconjuntos de $D$, que podem ser obtidos pelo axioma da separação da teoria $\mathfrak{Q} .^{24}$.

DEFINIÇÃo 5.2. um elemento $x$ dessa coleção (ou seja, um subconjunto de D) será:

\footnotetext{
${ }^{23}$ Observe-se que, dado que estamos tratando com $m$-átomos de $\mathfrak{Q}$, não podemos usar a igualdade.

${ }^{24}$ Este axioma é expresso assim: $\forall_{Q} x \exists_{Q} y \forall t(t \in y \leftrightarrow t \in x \wedge A(t))$, onde $A(t)$ é uma fórmula com $t$ livre. Intuitivamente, este axioma separa de um dado quase conjunto $Q$ os objetos $t$ que têm uma certa propriedade $A$.
}

Manuscrito - Rev. Int. Fil., Campinas, v. 37, n. 1, p. 117-164, jan.-jun. 2014. 
(a) do tipo $D_{1}$, se $q c(x)=3$ e os elementos de $x$ são um $e^{-}$, um $p$ e um $n$;

(b) do tipo $D_{2}$, se $q c(x)=6$ se seus elementos forem dois $e^{-}$, dois $p$ e dois $n$, e assim por diante.

Podemos supor que o quase-cardinal de $D$ é tão grande quanto necessário e, assim, podemos formar $n$ conjuntos do tipo $D_{1}, n$ do tipo $D_{2}$ etc., bem como subconjuntos de $D$ com mais elementos.

Definição 5.3. Chamaremos os qsets do tipo $D_{1}$ de "pré-átomos de Hidrogênio" (nomeados por $H$ ), os de tipo $D_{2}$ de "pré-átomos de Hélio" (nomeados por $\mathrm{He}$ ), e assim por diante.

Vale aqui chamar a atenção para alguns fatos. O primeiro é que os elementos da tabela periódica, como se sabe, não respeitam uma progressão aritmética (no sentido de que não temos os elementos como seguindo sempre uma sequência do tipo "elemento $1=$ um elétron, um próton, um nêutron", "elemento 2 = dois elétrons, dois prótons, dois nêutrons", "elemento $3=$ três elétrons, três prótons, três nêutrons" ...), mas sim temos elementos com número de partículas atômicas diferentes (por exemplo, a prata possui 47 prótons, 47 elétrons e 60 nêutrons). Deste modo, a quase-cardinalidade dos subconjuntos $D_{n}$ acima tem que ser dadas por definição 'uma a uma', já que só assim conseguimos realmente expressar o que acontece na realidade. ${ }^{25}$ Logo, o "assim por diante" da definição (b) acima, não deve ser entendido como um simples acréscimo de um $m$-átomo de cada tipo em cada uma das classes subsequente à $D_{2}$. Não obstante, como nosso domínio $D$ tem um número tão grande quanto o necessário de partículas atômicas, podemos construir

\footnotetext{
${ }^{25}$ Por exemplo, os elementos $x$ de um $D$ de tipo $D_{47}$ (que irão representar pré-átomos de prata) terão $q c(x)=154$, e seus elementos são exatamente 47 $p, 47 e^{-}$e $60 n$ : se a definição seguisse uma progressão aritmética, obteríamos algo como 'surplus elements', ou seja, elementos que estão definidos no nosso formalismo, mas que não existem na tabela periódica.
} 
novos (mais massivos) elementos se forem descobertos: em nossa formalização, basta definir 'tipos mais massivos' de conjuntos $D_{i}$, sendo que o número de elementos $\left(e^{-}\right),(n)$ e $(p)$ em cada um dos 'últimos' $D_{i}$ é sempre o número de elétrons, prótons e nêutrons do elemento mais 'massivo' da tabela periódica (até agora, o Ununóctio: ${ }_{118}$ Uuo). Lembramos, entretanto, que o rótulo subscrito "1", "2" etc. nos pré-átomos $D_{i}$ não devem ser entendidos como dando algum tipo de 'identidade' para estes átomos: desde que eles são construídos com $m$-átomos da nossa teoria $\mathfrak{Q}$, eles são indicerníveis por hipótese. Em segundo lugar, a representação acima é um tanto simplória, pois por exemplo estamos assumindo que todos os objetos quânticos de um mesmo tipo são indiscerníveis; como este é um estudo inicial, não vemos problema em continuar com esta hipótese.

Muller (2008) apresenta uma estrutura quântica para descrever o sistema físico composto de um átomo de Hélio (He) em um campo magnético uniforme $\left(B_{0}: \mathbb{R}^{3} \rightarrow \mathbb{R}^{3},\langle x, y, z\rangle \longmapsto\left\langle 0,0, B_{0}\right\rangle\right)$, da seguinte forma:

$$
H e=\left\langle L^{2}\left(\mathbb{R}^{3}\right), H\left(B_{0}\right), \psi, P r_{t}\right\rangle,
$$

onde $L^{2}\left(\mathbb{R}^{3}\right)$ é o conjunto básico, isto é, o espaço de Hilbert de funções complexas quadráticas de três variáveis (funções de onda complexas); $H\left(B_{0}\right): D \rightarrow L^{2}\left(\mathbb{R}^{3}\right)$ é o Hamiltoniano (o operador que representa a magnitude física da energia); $\psi$ é a solução da equação de Schrodinger, de modo que $\psi$ é uma função de $\mathbb{R} \rightarrow L^{2}\left(\mathbb{R}^{3}\right), t \rightarrow \psi(t)$ e é contínua se nenhuma medida é feita e, por fim, a função $\operatorname{Pr}_{t}: \Delta \mapsto \operatorname{Pr}_{t}(\Delta)$ é a medida da probabilidade (regra de Born), tal que para todo $t \in \mathbb{R}$, existe uma probabilidade de se encontrar um valor $\Delta \subset \mathbb{R}$ para a energia do átomo de Hélio quando medido em um estado $\psi(t)$. Todavia, diz Muller, normalmente os átomos de Hélio são caracterizados pelas suas partes constitutivas (um núcleo, consistindo de dois elétrons, dois nêutrons e dois prótons), bem como sua massa, carga e spin, e segundo o autor isso pode ser 'extraído' do hamiltoniano da estrutura, de 
modo que poderíamos assim representar um átomo de Hélio tanto pelo modo que estamos acima definindo, bem como pelo modo que Muller o fez. Como nos interessa aqui apenas a discussão relacionada à identidade dos compostos, podemos optar pelo modo mais simples, tendo em mente que poderíamos também ter uma representação atômica de tais objetos que usasse o Hamiltoniano e a função $\psi$. Um último ponto se refere ao fato de que como ainda não definimos o componente estrutural do átomo, no sentido da discussão tida anteriormente, convencionamos chamar tais átomos de "pré-átomos". Este ponto ficará mais claro na sequência.

A partir de tais postulados, podemos definir uma estrutura para os compostos químicos como uma $n$-upla da forma

$$
\mathfrak{M}=\langle D, \mathfrak{C}, R, M, E\rangle
$$

onde:

1. $D$ é um quase-conjunto, $\mathfrak{C}$ é uma coleção de subconjuntos de $D$ do modo acima definido;

2. $R$ é uma relação de indistinguibilidade $(\equiv)$ sobre o conjunto $D$, definida a partir dos axiomas (Q1), (Q2) e (Q3), de modo que se $\left(D_{x} \wedge D_{y} \wedge D_{z}\right) \in D$ então:

$$
\begin{aligned}
& \left(\equiv_{1}\right) \forall D_{x}\left(D_{x} \equiv D_{x}\right) \\
& \left(\equiv_{2}\right) \forall D_{x} \forall D_{y}\left(D_{x} \equiv D_{y} \rightarrow D_{y} \equiv D_{x}\right) \\
& \left(\equiv_{3}\right) \forall D_{x} \forall D_{y} \forall D_{z}\left(D_{x} \equiv D_{y} \wedge D_{y} \equiv D_{x} \rightarrow D_{x} \equiv D_{z}\right)
\end{aligned}
$$

Com isto, particionamos o domínio em classes indistinguíveis (no mesmo sentido - mas não igual — das classes de equivalência na matemática clássica). Isto porque, dada uma relação de indistinguibilidade $\equiv$ sobre o quase-conjunto $D$, e dado qualquer $D_{y} \in D$, podemos definir $\left[D_{y}\right]$ como o subconjunto de todos $D_{z}$ em $D$ tal que $D_{y} \equiv D_{z}$. $\left[D_{y}\right]$ é então chamado de '三-classe indistinguível de y'. É fácil provar que se 
$[\mathrm{y}] \neq[\mathrm{z}]$, então $[\mathrm{y}] \cap[\mathrm{z}]=\emptyset$. À classe de subconjuntos indistinguíveis 'tipo' $D_{1}$, (denotação: $\left[D_{1}\right]$ ), chamamos de classe dos pré-átomos de hidrogênio. À classe de subconjuntos indistinguíveis 'tipo' $D_{2},\left(\left[D_{2}\right]\right)$, chamamos de classe dos pré-átomos de Hélio, e assim por diante. A diferença desta abordagem é que na matemática clássica podemos provar que quando temos classes de equivalência, não conseguimos saber quando estamos falando dos elementos da classe ou da classe em si: a classe de equivalência, e os seus elementos, podem ser tomados como 'iguais' em certo sentido ${ }^{26}$. Mas aqui, como a construção é alicerçada na teoria de quase-conjuntos $\mathfrak{Q}$, podemos sempre saber se estamos falando sobre o elemento $\left(D_{n}\right)$ ou sobre a classe $\left(\left[D_{n}\right]\right)$. Isto porque podemos provar, nesta teoria, que a relação de indistinguibilidade (三) não é quid pro quo uma relação de equivalência como a da matemática clássica.

Como todas essas classes $\left[D_{n}\right]$ pertencem ao nosso domínio $D$, podemos definir uniões de elementos $D_{n}$ de cada classe $\left[D_{n}\right]$ para formar o conjunto $M$ de "pré-moléculas" da nossa estrutura $\mathfrak{M}$. Então, por exemplo, podemos definir (conjuntistamente) uma pré-molécula de água como sendo $\mathrm{H}_{2} \mathrm{O}=\mathrm{H} \cup \mathrm{O} \cup H=D_{11} \cup D_{81} \cup D_{12}$ tal que $\left(D_{11} \wedge D_{12}\right) \in\left[D_{1}\right]$ (ou à classe do pré-átomo de hidrogênio) e $D_{81} \in\left[D_{8}\right]$ (ou à classe do pré-átomo de oxigênio) ${ }^{27}$. Como enfatizamos acima, a forma como se deve 'somar' tais elementos para se construir uma molécula de água é algo que uma adequada mereologia química deve responder (abaixo falaremos mais disso). ${ }^{28}$

Não obstante, como também dissemos anteriormente, para construir uma molécula de água precisamos, primeiramente, somente de

\footnotetext{
${ }^{26}$ Sobre este ponto específico, ver Mendelson (1979, p. 83).

${ }^{27}$ Novamente alertamos que estes números não devem ser entendidos como dando algum tipo de identidade para os átomos.

${ }^{28}$ Por mereologia entende-se a lógica do todo e de suas partes, e foi iniciada no século XX por S. Lesniewicz; veja-se Luschei (1962); Simons (1987); Varzi (2012).
} 
dois átomos de hidrogênio e somente de um átomo de oxigênio. Como todos os nossos $D_{1}$ em cada $\left[D_{1}\right]$ são indiscerníveis, não importa qual particular átomo de hidrogênio tomemos ou qual átomo de oxigênio tomemos para formar essa molécula. Da mesma forma, se trocarmos um pré-átomo de hidrogênio por outro pré-átomo de hidrogênio na classe $\left[D_{1}\right]$, nada muda na pré-molécula (inobservabilidade de permutações). Neste sentido, consoante à química, toda pré-molécula de água é indiscernível de qualquer outra pré-molécula de água, e assim por diante, já que foram construídas com elementos indistinguíveis. Desta forma, vamos ao encontro tanto do pensamento de Penrose como de Dalton antes citados. Se quisermos costruir outros tipos de pré-moléculas, ou outras coleções de pré-moléculas, procedemos da mesma forma desde o início: como todas essas pré-moléculas foram construídas com partículas indistinguíveis, todas são indiscerníveis. Com isso, podemos considerar quase-conjuntos formados de pré-moléculas de água, de gás hélio, de cloreto de sódio etc.

Ainda que relevante, não poderemos discutir aqui tópicos como sobre quantos átomos de hidrogênio são necessários para se perfazer uma molécula de água, ou quais e quantas moléculas são necessárias para se constituir um polímero, ou como estes átomos e moléculas necessitam estar configurados geometricamente para se constituir estas moléculas ou compostos, ou quais tipos de ligações químicas são necessárias para que tal composto tome forma, pois tais assuntos não concernem ao problema lógico aqui discutido. Como sugerido anteriormente, isso tudo estará encerrado na parte $E$ da nossa estrutura, que deixamos para analisar mais detalhadamente em outro trabalho, a qual designa justamente a coleção de 'componentes estruturais' dos elementos (por exemplo, o componente geométrico, o componente 'tipo de ligação' (metálica, covalente, iônica etc) e assim por diante). Em cada caso, pode-se definir uma função $f$ com domínio E, o qset de componentes estruturais, no qset das pré-moléculas $M$, de modo que, para 
cada 'tipo' de pré-molécula exista um componente estrutural, também de cada tipo, ligado a ela. No mesmo sentido, podemos definir uma $f^{\prime}$ $E \mapsto D$ que "liga' cada $m$-átomo $(p)$ e $(n)$ de $D$ ao predicado "núcleo" em $E$, e o $m$-átomo $\left(e^{-}\right)$, por sua vez, ao predicado "nuvem eletrônica" em $E$, por exemplo. A partir da definição de tais q-funções ${ }^{29}$ podemos passar a chamar os subconjuntos $D_{n}$ de "átomos" propriamente, e as pré-moléculas de "moléculas" propriamente, finalizando assim (do ponto de vista lógico e conjuntista, repetimos) nossa estrutura química.

\section{Mereologia e quase-conjuntos}

O que construímos acima foi algo extremamente esquemático. Esperamos que tenha ficado claro o papel da "estrutura" $E$ em nosso esquema acima, que deve ser introduzida caso a caso, dependendo do elemento considerado. Na verdade, o que pretendemos foi apenas alertar para o problema lógico aqui existente de se fundamentar a química, e em especial a noção de não-individualidade dos compostos químicos, que deve ser olhada com cautela se formos utilizar a lógica e uma teoria de conjuntos clássica para fundamentar qualquer teoria que deles queira tratar. Em nenhum momento queremos dizer que o esquema acima realmente 'representa' um átomo ou uma molécula, mas apenas que ela pode ser encarada como um esquema lógico-matemático-conjuntista de uma possível representação, e que se formos nessa direção, não podemos nos abster de enfrentar a problemática lógica aqui discutida.

Com efeito, o modo como os componentes de átomo ou de uma molécula se 'somam' para constituírem um elemento químico é matéria de longo debate na filosofia da química. Em especial, tal estudo é compreendido dentro da química por alguma forma de mereologia,

\footnotetext{
${ }^{29} \mathrm{Na}$ teoria de quase-conjuntos, a ideia de quase-função generaliza a de função usual, levando objetos indiscerníveis em objetos indiscerníveis. Para a definição precisa, consultar French e Krause (2006).
}

Manuscrito - Rev. Int. Fil., Campinas, v. 37, n. 1, p. 117-164, jan.-jun. 2014. 
que é a disciplina que estuda as relações parte-todo. Com efeito, como diz Sukumar (2013), a identificação de uma entidade em uma molécula, como um átomo, é um construto mereológico que é central em química. ${ }^{30} \mathrm{Na}$ lógica, primeiramente, o estudo de tais relações foi devida ao trabalho de Lesniewski; ${ }^{31}$ nas mereologias usuais, os 'todos' são compostos de partes distinguíveis, que também podem ser compostos de partes distinguíveis. Todavia, alerta Sukumar (2013), as mereologias usuais falham em estruturar mereológicamente entidades como moléculas, onde o todo não é meramente a soma das partes. A física quântica dá uma ilustração vívida da falha da mereologia clássica se lançarmos mão da regra de Born. Neste caso, se temos uma função de onda $\psi_{1}$, com probabilidade igual a $P\left(\psi_{1}\right)=\left|\psi_{1}\right|^{2}$; sendo superposta com uma função de onda $\psi_{2}$, com densidade de probabilidade $P\left(\psi_{2}\right)=\left|\psi_{2}\right|^{2}$, a probabilidade da densidade da onda superposta $\psi_{1}+\psi_{2}$ é dada por:

$$
P\left(\psi_{1}+\psi_{2}\right)=\left|\psi_{1}+\psi_{2}\right|^{2}=\left|\psi_{1}\right|^{2}+\left|\psi_{2}\right|^{2}+2 \operatorname{Re}\left(\left\langle\psi_{1} \mid \psi_{2}\right\rangle\right),
$$

que não é a soma das probabilidades individuais $\left|\psi_{1}\right|^{2}+\left|\psi_{2}\right|^{2}$ devido ao "termo de interferência"adicional. Além disso, na superposição de estados como os acima, faz com que um 'todo' não possa ser visto como formado por 'partes', pois essas partes não podem ser 'separadas' a não ser por uma medição. Além do mais, em um composto (um "todo") em física e em química quânticas contém "partes" que são indiscerníveis de outros elementos (como elétrons são indiscerníveis e elétrons), e são tais que a substituição (permuta) de um desses elementos por outro similar (de mesmo tipo ou espécie) não acarreta mudança perceptível

\footnotetext{
${ }^{30}$ Escusado dizer que esse ponto também não é unânime: com efeito, Llored e Haré (a aparecer) não partilham dessa posição, afirmando claramente que "we have argued elsewhere that atoms do not have entity-like constituents -it is a mistake to treat electrons as constituents of anything".

${ }^{31}$ Ver Varzi (2012). Um tratamento mais extenso encontra-se em Simons (1987).
} 
nesse "todo" (Krause (a aparecer)). Isso traz um outro tipo de problema para tentarmos aplicar as mereologias "usuais" neste contexto, pois nelas, "todos" compostos de "partes" idênticas são idênticos, mas aqui parece que deveríamos falar que esses "todos" são indiscerníveis quando compostos de partes indiscerníveis (desde que consideremos a forma, o que em nossa abordagem, como vimos, é captada pela parte " $E$ "da estrutura).

Dado problemas como os acima, a química guardou o 'aspecto geral' da mereologia Lesniewskiana e criou algumas possíveis mereologias mais próximas do o que o químico entende por átomos, moléculas e compostos (Llored e Harre (a aparecer)). A nossa proposta segue nesta direção. Todavia, também não há unanimidade sobre qual mereologia adotar e de como devemos entender essa mereologia. Dependendo da abordagem, a molécula pode ser descrita como um todo (no sentido de algo 'inseparável') (Mulliken (1932)), ou como um agregado de átomos, ${ }^{32}$ ou ainda 'aplicando' uma densidade eletrônica em um espaço dividido em 'grides' de um tipo e tamanho particular (Kohn et. ali. (1996)). Sukumar (op. cit.), por exemplo, em seu artigo lista ainda outros três tipos de mereologia (a mereologia de Bader, de Hirshfeld e via espaço-momento), e afirma que não temos ainda boas indicações para escolher uma delas em detrimento a outras. Além disso, alerta ele, a modificação das leis básicas de cada mereologia leva à diferentes concepções de átomos na molécula, o que faz a escolha da mereologia não ser realmente algo simples. Não obstante, entre todas as mereologias existentes, duas delas são mais debatidas na filosofia da química, talvez por serem as primeiras aventadas: são as chamadas "mereologia clássica - C" e a "mereologia de Lewis - S". Aqui, não faremos uma discussão particular sobre as outras mereologias listadas acima, mas ficaremos restritos somente a essas duas mereologias mais usuais, de

\footnotetext{
${ }^{32}$ Segundo Llored e Harre (a aparecer), Linus Pauling foi o primeiro a adotar essa posição.
}

Manuscrito - Rev. Int. Fil., Campinas, v. 37, n. 1, p. 117-164, jan.-jun. 2014. 
modo a apenas levantar alguns aspectos dessas construções em relação à nossa estrutura química e a teoria de quase-conjuntos.

A mereologica clássica (C) repousa, dentre outros, sobre dois princípios básicos. O primeiro é o princípio da composição única, de acordo com os qual existe um único ser, que é a soma ou fusão de certas coleções de seres das quais todo ser é parte e que não tem partes outras que tais partes. ${ }^{33}$ Desta forma, uma molécula é uma única "soma" de certos átomos químicos. Todavia, como argumentamos anteriormente, a simples soma de tal coleção não serve para identificar uma molécula como sendo de um certo tipo, de modo que devemos também incluir certas regras estruturais como 'componente' dessa molécula ( cf. Llored e Harre (a aparecer)). Isso, basicamente, foi o que defendemos que de ser enquadrado na parte "E" da nossa estrutura, tal como enfatizamos na seção anterior. Além do mais, como dito, uma dessas totalidades é em geral indiscernível de outras do mesmo tipo (moléculas de um mesmo composto), o que não é levado em conta na mereologia C.

O segundo princípio da mereologia clássica é o da transitividade mereológica: se $\mathrm{B}$ é parte de $\mathrm{A}$, e $\mathrm{C}$ é parte de $\mathrm{B}$, então $\mathrm{C}$ é parte de $\mathrm{A}$. Segundo Harré e Llored (2011), esta última regra possui várias exceções: uma engrenagem é parte da caixa de engrenagens, mas um dente de uma engrenagem é parte da engrenagem no mesmo sentido que a engranagem é parte da caixa? Elétrons não são partes de átomos do mesmo modo que patas são partes de cavalos, por exemplo, mas selas, por sua vez, já não são partes dos cavalos da mesma forma que as patas o são. Com certeza, dizem os autores, se incluirmos algo tipo a "função" das partes sobre os atributos que definem o que é parte do que, então claramente o dente é parte da engrenagem de um modo diferente da engrenagem em relação à caixa, de modo que parece que a relação

\footnotetext{
${ }^{33} \mathrm{O}$ conceito de soma mereológica é central em qualquer mereologia, mas não a daremos aqui porque demandaria que vários outros conceitos fossem introduzidos. Ver Simons (1987).
} 
mereológica clássica acima necessita ser complementada. Esta observação levou à necessidade de se formular uma segunda mereologia clássica, uma na qual também se inclua princípios funcionais-estruturais. Agora, se quisermos saber como nosso componente cabe num todo, podemos procurar também levar em conta a potencialidade funcional que de algum modo age na decomposição do original por inteiro. Estes aspectos foram discutidos por Oppenheim e Rescher (1955), que sugerem três condições 'funcionais' sobre o todo e suas partes: 1) um todo deve possuir um atributo que é peculiar somente a ele; 2) as partes do todo devem estar em alguma relação especial uma com a outra, e 3) o todo deve ter uma estrutura. Na merologia clássica, assim, os três átomos de uma molécula de água são partes da molécula de água, mas devese também assumir nesse caso tanto a estrutura da molécula de água, bem como a função de suas partes indivíduais em relação ao todo. Em resumo, a abordagem clássica passa então a entender uma molécula como sendo uma grande fusão de átomos sustentados por seus poderes de combinações individuais. Não obstante, o que nos interessa discutir é exatamente como podemos definir formalmente essa idéia de "parte" e de "fusão de partes" às quais devem ser somadas as características estruturais e funcionais. Isso pode ser feito em termos conjuntistas? A resposta não é simples, e deve ser procurada com motivação na química. Ademais, cabe aqui mais uma observação: em 1) acima, é dito que um todo deve ter um atributo que lhe seja peculiar. Qual seria esse atributo no caso de um composto químico? Do que ele dependeria? De seus componentes, que em suma recairiam na peculiaridade dos compostos elementares, como prótons e elétrons? Ou então de algum tipo de localização espaço temporal? É patente que isso não é claro e que não há respostas fáceis a essas questões.

A outra mereologia que citaremos aqui é a de Lewis (Harré e Llored (2011)). Segundo este autor, no caso de uma mereologia para os 'objetos' da química, a pertinência conjuntista não deveria ser tomada 
como representando a mesma relação como parte-todo (o que parece bastante óbvio). Todavia, na mereologia de Lewis, são admitidas classes que têm partes, suas subclasses, de modo que fica aberta a possibilidade de uma teoria mereológica de conjuntos — ou uma mereologia teórico conjuntista - a la Lewis, por assim dizer. Ele então propõe diversos princípios mereológicos para (seus) conjuntos, subconjuntos e superconjuntos, e suas relações com indivíduos (os quais não explicitaremos aqui). Usando o conceito de fusão, Lewis refina a mereologia Lesniewskiana com princípios adicionais de modo a se obter uma mereologia na qual a fusão de indivíduos não geram conjuntos. A questão que se põe é até que ponto a mereologia de Lewis apresenta alguma vantagem sobre a mereologia clássica, e (novamente) até que ponto se pode representar as classes de Lewis através de formalizações conjuntistas. Não obstante, dizem Harré e Llored (2011), a mereologia de Lewis deixa de fora aspectos estruturais, bem como não admite mudanças qualitativas dos compostos químicos e dos membros de suas clásses lógicas, o que leva a vários contra-exemplos baseados nos princípios da química. Segundo esses autores, o discurso químico é baseado na distinção, às vezes complicada, entre elementos, compostos e misturas, o que é evidentemente estruturada em compostos mereológicos. Elementos são fusões ou somas uniformes de núcleos de átomos. Compostos também são somas, bem como as misturas também o são, pois suas fusões ou somas das suas partes não são casualmente relatadas: novamente, se faz necessária a noção de estrutura da qual eles fazem parte. Aqui se nota outra vez como o caráter estrutural dos elementos químicos realmente deve ser incluído na nossa formalização, de modo que se um dia se puder 'completar' a mereologia de Lewis com características estruturais, e se se puder representar isso em uma estrutura quase-conjuntista, a estrutura acima erigida pode muito bem dar conta - pelo menos do ponto de vista formal — de tal representação.

Como dito acima, qual a mereologia escolher é matéria de intenso Manuscrito - Rev. Int. Fil., Campinas, v. 37, n. 1, p. 117-164, jan.-jun. 2014. 
debate na química. Inclusive, para Harré e Llored (2011), ambas as mereologias (bem como as outras que existem: Simon, Earlay, Needhan etc) deveriam ser complementadas com a noção de 'contexto' onde se apresentam os compostos químicos. Em tal 'contexto', podem ser incluídas tanto noções como "aparato experimental", bem como "prática química", a quais dependem da situação e do caso estudado. Devemos, dizem eles, ter tais suposições em mente antes de maiores discussões sobre mereologia: não podemos estudar todas as características moleculares por meio de um simples nível de cálculo. Isto porque, na química quântica, a mereologia usada pelos químicos liga o inteiro, suas partes, e muitas vezes também o seu ambiente. Ela não é assim uma mereologia que faz uso somente das partes para se definir o todo univocamente; mas sim é uma que deve ser tomada junto com um contexto que representa (entre outras coisas) o modo de acesso - cognitivo ou experimental - ao elemento em análise. A prática química necessita assim do todo, das partes, e de todas as outras entidades contextuais ao mesmo tempo, de modo a se tornar uma "mereologia relacional" (Harré e Llored (2011)). Para tais autores, as partes são embebidas em uma prática química enganjada de investigação, e a mereologia necessita incluir os modos de acesso para estabelecer como a relação parte-todo deve ser usada. O modo de operação não pode ser eliminado, já que ele também determina como o todo e suas partes estão relacionadas: de acordo com o tipo de de análise impingida sobre o elemento, a mesma composição - no final do processo - pode não ter até mesmo as mesmas partes-todo. ${ }^{34}$ Em resumo, para Harré e Llored, os predicados do discurso químico são assim todos contextos-sensitivos: as partes não são assim algo intrínseco, de modo que só podemos conhecer as interações e não a realidade isolada de nós. Na filosofia, é sabido como esse debate é antigo, de modo que vemos como a química realmente necessita se aproximar do debate filosófico.

\footnotetext{
${ }^{34}$ No texto citado, podem ser vistos vários exemplos desse fato.
} 
A revisão dos trabalhos citados nos parece importante porque eles apontam parcialmente para questões que temos destacado aqui. Com efeito, uma das questões primárias para um filósofo da química seria exatamente decidir se os conceitos químicos chaves tais como substância, elemento, molécula, átomo etc., bem como suas interações mereológicas, podem realmente caber - no mínimo em parte - sobre a (ou uma) teoria de conjuntos, tal como tentamos fazer aqui. ${ }^{35}$ Entre as questões presentes nessa discussão, está exatamente a de se definir se os constituintes atômicos das moléculas são realmente partes simples que são subconjuntos de partes moleculares, bem como se há um modo teórico-conjuntista-mereológico de se distinguir misturas de compostos, por exemplo. Assim, como já discutimos, faz algum sentido perguntar se os elementos e seus constituintes podem ser tratados como conjuntos? Neste sentido, são os átomos de oxigênio e hidrogênio subconjuntos da molécula de água? Se sim, no mínimo eles devem fazer de um 'super-conjunto' chamado ‘água'. Todavia, embora eles ainda sejam partes de tais moléculas, átomos de vários tipos não constituem moléculas no mesmo modo que seus membros de conjuntos fazem conjuntos. Cavalos perfazem um conjunto de cavalos ${ }^{36}$ por exemplo, mas tais conjuntos são diferentes exatamente porque cavalos nunca se fundem em quantidades equinas maiores do mesmo modo que o sódio se funde em maiores blocos de sódio. Além disso, outra questão importante é decidir se a diferença estrutural pode ser um mero ad hoc 'adicionado' sobre a mereologia. Isto porque sabemos que somente acidentalmente

\footnotetext{
${ }^{35}$ Como se sabe, Goodman inicialmente valeu-se de uma teoria de conjuntos (o mesmo fez Tarski) em seu "cálculo de indivíduos", escrito conjuntamente com Leonard, mas posteriormente eliminou a teoria de conjuntos devido às suas crenças nominalistas — ver Krause (a aparecer).

${ }^{36}$ Estamos falando metaforicamente para enfatizar o ponto principal. A rigor, é um absurdo dizer que cavalos formam um conjunto, já que um conjunto é uma entidade abstrata e seus elementos também, e cavalos, supostamente, não são.
}

Manuscrito - Rev. Int. Fil., Campinas, v. 37, n. 1, p. 117-164, jan.-jun. 2014. 
um conjunto pode ter algo tipo 'propriedades estruturais' (que devem além disso serem geridas por axiomas específicos), já que é um objeto abstrato conceitual. Uma molécula, por exemplo, tem propriedades estruturais porque é uma entidade material que tem relações materiais entre suas partes. Um conjunto, por sua vez, é um objeto lógico e abstrato, vivendo numa hierarquia conjuntista 'fora' da realidade material. Se pergunta-se então sobre a validade de um sistema estrutural como fizemos acima, em que as diferenças estruturais tem que ser adicionadas ad hoc sobre a mereologia, não vemos alternativa além de dizer que sim, mas que este ad hoc é o que mais relevante podem nos apontar as disciplinas das ciências empíricas. Seria tarefa do químico, a partir de sua pesquisa, apontar para essa estrutura, enquanto é tarefa do lógico dotar essa construção de um formalismo correto supondo que ela exista No nosso caso, o que estamos defendendo é que o formalismo mais adequado para sustentar uma visão mereológica conjuntista deverá ser dada em uma teoria de quase-conjuntos, exatamente porque inerente a todo esse questionamento está o problema da identidade de tais compostos e sua relação com as teorias formais clássicas. Isso, como estamos enfatizando, abre uma nova dimensão na qual uma mereologia qualquer deve olhar de modo a buscar suplementação, tanto teórica como formal, e pode-se dizer assim que um novo conjunto de regras mereológicas-conjuntistas mais 'honesta' também parece ser necessária para a lógica do discurso químico.

Como já enfatizado, uma primeira mereologia quase-conjuntista pode ser vista em Krause (a aparecer), e aqui nos contentamos em apontá-la.

\section{Conclusão}

Como visto, com a estrutura conceitual desenvolvida acima, podemos dar uma fundamentação quase-conjuntista para átomos e molécuManuscrito - Rev. Int. Fil., Campinas, v. 37, n. 1, p. 117-164, jan.-jun. 2014. 
las dos mais variados tipos. Neste artigo, iniciamos nossa construção com partículas elementares (prótons, elétrons e nêutrons), mas todavia tal construção pode ser extendida de modo a se começar com partículas subatômicas, como os quarks, léptons, mésons etc. Além disso, vale ressaltar que o que obtemos, por assim dizer, foi uma estrutura geral dos compostos químicos, estrutura esta (e este é um ponto importante) que não é comprometida com a identidade (no sentido clássico) dos compostos envolvidos - apesar de necessitar ser completada em cada caso pela 'função' $f(E)$, como salientado. De qualquer forma, a construção aqui apresentada não exclui a possibilidade de se encontrar, no futuro, alguma estrutura que possa continuar a ser geral, mas que não necessite de ser completada em cada caso como aqui foi feito. Como dissemos, este é um problema em aberto.

O nosso propósito, neste artigo, foi apenas mostrar como podemos de certo modo 'construir' átomos e moléculas com o arcabouço lógico e matemático da teoria $\mathfrak{Q}$, e as vantagens desta construção em relação a qualquer outra abordagem deste tipo que utilize, por sua vez, as teorias padrão de conjuntos. É claro que "construir" conceitualmente um átomo não é algo tão simples como aventamos acima: tal como enfatizamos, talvez tenha que se levar em conta uma mereologia, bem como várias características que talvez apenas o químico possa fornecer. Todavia, nosso principal objetivo foi alertar para a problemática da identidade de tais compostos e a relação de tal conceito com as teorias de conjuntos padrão. Como enfatizamos, com a teoria de conjuntos alternativa que apresentamos acima, podemos ter coisas "iguais" que não são apenas uma (problema que ocorre no caso usual dos conjuntos ou das mereologias usuais), já que restringimos a aplicações do símbolo de igualdade para somente alguns elementos nesta teoria (para os elementos 'clássicos', como visto). Agindo assim, não necessitamos usar em nossa teoria qualquer 'suplemento artificial' (como os postulados de simetria), haja visto que assumimos a indistinguibilidade de certos 
objetos desde o incício, de modo que o formalismo se torna assim mais natural. É óbvio que essa construção talvez não seja a única possível: talvez um outro tipo de abordagem possa existir, até mesmo de uma forma mais econômica do que fizemos aqui. Não obstante, acreditamos que todas as abordagens que podem vir a ser feitas precisam 'evitar' o problema da identidade dos átomos e moléculas e não poderão, então, ser ancoradas numa teoria de conjuntos como a ZFU (ou outra qualquer teoria de conjuntos padrão) devido aos problemas mostrados: se utilizarmos a matemática clássica, nos comprometemos também com a teoria de conjuntos clássica e, nessas teorias, coisas iguais significam apenas uma coisa. Deste modo, se partirmos dessas construções clássicas, podemos falar sobre os elementos da natureza - do modo que o químico faz - somente de uma forma 'metafórica' pois, a rigor, o que se diz usualmente sobre a indiscernibilidade dos compostos parece ferir a lógica clássica.

Em geral, o químico não se ocupa com tais sutilezas filosóficas. Porém, de um ponto de vista filosófico elas são importantes, haja visto que temos, em certa acepção, uma 'falta de conexão' entre a realidade (a natureza), as teorias que descrevem o funcionamento desta realidade (a química no caso aqui em apreço), e as teorias que alicerçam tais teorias (em nosso caso, a matemática e a teoria de conjuntos clássica). De qualquer modo, acreditamos que a abordagem por nós aventada pode, no mínimo, ajudar outros trabalhos de filosofia da química a terem mais fundamentação teórica, principalmente quando estes falam de conjuntos de elementos, átomos e moléculas. 


\section{Referências}

ARENHART, J. B., \& KRAUSE, D. "Identidade, individualidade e quase-conjuntos". Revista Eletrônica Informação e Cognição, vol. 6, no. 2, p. 25-39, 2007.

ARNDT, M. et al. "Wave-particle duality of C60 molecules". Nature 401, 680-682, 14.October, 1999.

BALL, D. W. Physical chemistry. Pacific Goove: Brooks/Cole, 2003.

BRANCIARD, C., R., D., LIANG, Y-C, e GISIN, N. "MeasurementDevice-Independent Entanglement Witnesses for All Entangled Quantum States". Physical Review Letter 110, 060405, 2013.

COX, P. A. Instant notes [in] inorganic chemistry, 2a. ed. London: Bios Scientific Publishers, 2004.

da COSTA, N. C. A. e FRENCH, S. Science and Partial Truth: a unitary approach to models and scientific reasoning. Oxford: OUP, 2003.

DALTON, J. A new system of chemical philosophy. London: Printed by S. Russell, 1808 .

FRENCH, S. \& KRAUSE, D. Identity in Physics: A historical, philosophical and formal analysis. Oxford: OUP, 2006.

GRIFFTHINS, D. Introduction to Quantum Mechanics. 2nd.ed., New Jersey: Printice Hall, 2004.

JAMMER, M. The Conceptual Development of Quantum Mechanics. New York: McGrall-Hill, 1966.

LLORED, J.-P., \& HARRÉ, R. Developing the Mereology of Chemistry (a aparecer).

KETTERLE, W. When atoms behave as waves: Bose-Einstein condesation and the atom laser. Nobel Lecture, December 8, 2001, disponível em http://www.nobelprize.org/nobel_prizes/physics/ laureates/2001/ketterle-lecture.pdf. 
KLEIN, U., e LEFÉVRE, W. Materials in eighteenth-century science: a historical ontology. Cambridge: The MIT Press, 2007.

KOHN, W., BECKE, A. D. \& PARR, R. G. "Density functional theory of electronic structure". Journal of Physical Chemistry, 100, 12974-12980, 1996.

KRAUSE, D. "Is Priscilla, the trapped positron, an individual? Quantum physics, the use of names, and individuation." Arbor 187 (747), 61-66, 2011.

—. "Quantum Mereology" (a aparecer).

KUHN, H., FORSTERLING, H.-D. \& WALDECK, D. H. Principles of physical chemistry. New York: John Wiley \& Sons, 2009.

LEIBNIZ, G. W. 'Monadalogia', in "Os Pensadores". São Paulo: Abril Cultural, 1980.

LUSCHEI, E. C. The Logical Systems of Lesniwski. Amsterdam, NorthHolland, 1962.

MCQUARRIE, D. A., \& SIMON, J. D. Physical chemistry: a molecular approach. Sausalito: University Sience Books, 1997.

MENDELSON, E. Introduction to mathematical logic, 2a. ed. Monterey: Wadsworth Advanced Books \& Software, 1979.

MULLER, F. A. "The Characterisation of Structure: Definition versus Axiomatisation". (to appear in the) Proceedings of an ESF Conference, Vienna, 2008.

MULLIKEN, R. S. "Electronic structures of polyatomic molecules and valence III: quantum theory of the double bond". Physical Review 41, 754, 1932.

MUNFORD, S. (ed.) Russell on Metaphysics: Selections from the writings of Bertrand Russell. London and New York: Routledge, 2003.

MURPHY, B., MURPHY, C. \& HATHAWAY, B. J. Basic principles of inorganic chemistry: making the connections. London: The Royal Society of Chemistry, 2008. 
OPPENHEIM, P. \& RESCHER, N. "Logical Analysis of Gestalt Concepts". British Journal for the Philosophy of Science, vol. 6, 89-106, 1955.

PENROSE, R. The emperor's new mind. Oxford: OUP, 1989.

POMARICO, E. et al. "Various quantum nonlocality tests with a commercial two-photon entanglement source". Physical Review A 83, 052104, 2011.

REDHEAD, M., \& TELLER, P. "Particles, particle labels, and quanta: the toll of unacknowledged metaphysics". Foundations of Physics 21, pp. 43-62, 1991.

_. "Particle labels and the theory of indistinguishable particles in quantum mechanics", British Journal for'the Philosophy of Science 43, pp. 201-18, 1992.

RESTREPO, G., LLANOS, E.J., \& MESA, H. "Topological space of the chemical elements and its properties". Journal of Mathematical Chemistry 39, 401-416, 2006.

HARRÉ, H. \& LLORED, J.P. "Mereologies as the Grammars of Chemical Discourses". Foundations of Chemistry 13, pp. 63-76, 2011.

ROVELLII, C. What is Time? What is Space? Roma: Di Renzo Editore, 2006.

SIMONS, P. Parts: a Study in Ontology. Oxford: Clarendon Press, 1987.

SUKUMAR, N. "The atom in a molecule as a mereological construct in chemistry". Foundations of Chemistry 15 (3) pp. 303-309, 2013.

SUPPE, F. (ed) The Structure of Scientific Theories, 2a. ed. Illinois: Un. Illinois Press, 1977.

SUPPES, P. Axiomatic Set Theory. New York: Dover, 1972.

TELLER, P. An Interpretative Introduction to Quantum Field Theory. Princeton: Princeton University Press, 1995.

TURRELL, G. Mathematics for chemistry and physics. London: Academic Press, 2002. 
VARZI, A. "Mereology", The Stanford Encyclopedia of Philosophy (Winter 2012 Edition), Edward N. Zalta (ed.), URL = <http:// plato.stanford.edu/archives/win2012/entries/mereology/ $>$.

van HEIJENOORT, J. From Frege to Gödel: a Source Book in Mathematical Logic, 1897-1931. Harvard: Harvard University Press, 1967.

ZERMELO, E. "Investigations in the foundations of set theory, I", in van Heijenoort, J. (1967), pp. 199-215. 